New Worlds in Chemistry. By Martin Sherwood. Pp. 234. (Faber and Faber: London, 1977.) £6.95.

WITHOUT CHEMISTRY and the great industries based upon it, material civilisation as we know it has no future. The enormous changes which have taken place in the pattern of our daily lives during the past century or so have depended almost entirely on the progress of chemistry-the most central of the sciences whose tentacles reach out through all the others. Without it, the translation of most of the discoveries made in other sciences into practical, usable forms would simply not have occurred; and what is true of the past will be equally true in the future. Despite this, chemistry is undoubtedly less well known and well regarded than, for example, physics or biology by the general public, and it is rarely the subject of popular presentations on radio, television, or in the press. There is no single reason for this state of affairs, but from the many that could be adduced I would choose two as being of major importance.

The first is that the very ubiquity of chemistry and its products makes it a generally accepted part of everyday life to be noticed only when something untoward occurs, whereupon the public reacts with a display of frequently unfounded fear or panic. People, in other words, are aware of chemistry only dimly through its products or applications and are, for the most part, ignorant of or indifferent to the science itself.

The second is that chemistry, however absorbing it may be to its adherents, is inherently difficult to 'popularise'. To be understood, it requires acceptance of certain abstract concepts such as valency, bonding, and three-dimensional orientation of valencies, which have no real counterpart in everyday life. As a result the 'man-in-the-street' is usually unable to appreciate the chemist's ideas of molecular structure and interactions. This inability is not in my view simply due to chemical jargon. Be that as it may, popular expositions of the science have been few in number and successful ones even fewer. The appearance of New Worlds in Chemistry is therefore of more than passing interest.

In his new book, Dr Sherwood has done an excellent job of putting across a picture of modern chemistry in action. I found it extremely readable-journalistic here and there, perhaps, but probably none the worse for that. It seems to me that he has been successful because, accepting the ubiquity and maturity of the science, he devotes most

of his attention not to the search for spectacular events but to emphasising and exemplifying the part chemistry has played in a number of important developments in industry, in biology and in medicine, and in efforts to understand the origin of life on our planet.

The book opens with two chapters (47 pages in all) on the "Elements" and "Mechanics" of chemistry. Together they form a praiseworthy attempt to give a comprehensible yet reasonably accurate picture of the basis of chemistry today. I found it both readable and informative, but I was left wondering whether the general reader with no previous knowledge of chemistry would not still be in something of a fog after reading it.

The chapter on "Chemistry in the Beginning" gives a very - and perhaps undulyfull account of work on and theories relating to the development of organic compounds of varying complexity under prebiotic conditions. Opinions vary about the value of much of the work on pre-biotic synthesis, since it is hardly surprising that organic compounds could be produced in conditions which would not support life as we know it. What would be far more

\title{
Vibrations of crystals
}

Vibration Spectra and Symmetry of Crystals. By H. Poulet and J. P. Mathieu. Translated by A. Simievic. Pp. xiv +571 . (Gordon and Breach: New York, London and Paris, 1976.) $£ 26$.

Professor Mathieu is well known in France as an author of textbooks on the vibrational spectra of molecules and crystals. This book has evolved from one published in 1945. It is a translation of the original French edition of 1970; unfortunately, this is not stated anywhere in the book.

There are ten chapters on theory. They deal with the symmetry and internal structure of crystals, crystal dynamics, the symmetry of vibrations, and the classical and quantum theories of optical phenomena. The last chapter describes applications of the theory to infrared and Raman crystal spectra. There are seven appendices (on group theory and on X-ray and neutron diffraction), and a bibliography giving 185 refenences. The objective was "to give a systematic survey of the methods used to count the principal vibrations interesting would be the beginning of organisation--the appearance of coupled reactions under close control which is surely the real beginning of life; but of that we still know little.

The sections on the chemistry of life and death, on industrial chemistry and on the significance of chemistry in a variety of human activities from agriculture to fine art are well done, and the book closes with a chapter on "Chemistry and Tomorrow." In this chapter Dr Sherwood is brief and cautious in forecasting likely areas of advance but he devotes a good deal of space to the well worn question of the relationship between science and government, and the social responsibility of the scientist. These subjects are, of course, controversial but the author is right to point out the dangers inherent in the growing public awareness of the large scale effects which can be produced by modern technology and the need to prevent disillusion with science by the provision of adequate information. Taken as a whole New Worlds in Chemistry is a contribution to this end and it can be recommended to the general reader.

Lord Todd is President of the Royal Society and Master of Christ's College, Cambridge. of crystals, to determine their symmetry, to investigate their interactions with electromagnetic radiation and to establish the selection rules to which they are submitted".

The book has been written in a clear and helpful style, and will be useful to physicists and chemists concerned with the vibrations of crystals. Unfortunately, the translation is not always good-words such as "inequally", and phrases such as "integer multiple" and "allows to reduce their number" are to be found throughout; "et" occurs in the references instead of "and". An old value is used for the velocity of light, and SI units are not always used. There is a reference to Kitaigorodskii's 1961 book rather than to his Molecular Crystals and Molecules, published in 1973. There is no discussion of non-linear optical properties such as stimulated Raman scattering and the hyper-Raman effect.

A. D. Buckingham

A. D. Buckingham is Professor of Chemistry at the University of Cambridge, UK. 